\title{
Design challenge of a new monolithic concept for the main landing gear bay of a large passenger aircraft
}

\author{
Pietro Cerreta ${ }^{1, *}$, Paola Iaccarino ${ }^{2}$, Massimo Viscardi ${ }^{3}$, and Maurizio Arena ${ }^{3, *}$ \\ ${ }^{1}$ Protom Group S.p.A., Aerospace division, Via Vicinale S.M. del Pianto - CPN, Ed. 680143 - \\ Naples, Italy \\ ${ }^{2}$ LAER Group S.p.A., Aeronautical manufacturing, Via Caracciano 57/63 82011 Airola (BN) - Italy \\ ${ }^{3}$ Department of Industrial Engineering - Aerospace section, University of Naples "Federico II", \\ Via Claudio, 21, Naples, 80125, Italy
}

\begin{abstract}
In this paper, ITEMB team in the contest of the Clean Sky 2 framework, with the scope of a new architecture for the Main Landing Gear of a single isle aircraft type, presents its development in designing the two major item of the Main Landing Gear Bay that are the "roof" and the "rear pressure bulkhead" using pre-preg CFRP material. Typically, a lot of parts (metallic and also composite made) are involved in the two items manufacturing: the research effort has targeted the design of one piece structures consisting in a monolithic "roof" and "monolithic "rear pressure bulkhead". The assembly of these ones takes advantages from a hole-tohole assembly supported by statistical analysis. The main expected advantages are the reduction of: both non-recurring and recurring cost, the overall flow time and weight saving. The ITEMB (InTEgrated Main landing gear Box) team has worked adapting a bag-to-bag technology to the geometrical and strength capability requirements of the component and outcome of the research (not yet concluded at time of issuing this paper) includes: A design principle supported by stress analysis for strength, stability and local main load introduction; A manufacturing trials campaign to reach the possess of a robust process; A limited coupons test campaign to demonstrate that no specific critical items exists in the design approach. Finally, participants have acquired a new design and manufacturing technique, applicable also to other Aircraft components upgrading their capabilities and European strength in composite structures manufacturing.
\end{abstract}

\section{Introduction}

Research and technological innovation are making significant improvements in the aeronautical structures in recent years. Composite materials with increasing performance have been developed to increase functionality while optimizing costs and weight penalties, [1-4]. Within European Research Program Clean Sky 2, AIRBUS issued a Call for Proposal

\footnotetext{
* Corresponding author: pietro.cerreta@protom.com
} 
looking for a new design of Main Landing Gear Bay compliant with New Landing Gear Installation and using composite material.

Compared to present Single Aisle Aircraft configuration, challenging targets were assigned to the configuration:

- $\quad 0-5 \%$ Recurring Cost Saving;

- $\quad 5-10 \%$ Weight reduction;

- Assembly Flow Time decrease to achieve the targeted production rate of $50 \mathrm{~A} / \mathrm{C}$ per month.

TRL to start was TR2 and target TRL3. ITEMB staff has hardly worked on design/process innovation/optimization without using over-expensive materials and manufacturing process too far from industrial application. The following are the driving concepts:

- CFRP extended use with "design tailored" composite structure;

- Integrated Structure as much as possible;

- Higher cost of CFRP balanced by reduced time of assembly and more automation;

- $\quad$ Automated process (F/CTLM, AFP) as much as possible, to reduce production flow time;

- Limited use of Titanium;

- Risk reduction by fabrication and inspection of a representative/simplified item to demonstrate feasibility of innovative approach;

- Cost target;

- Weight target.

\section{Component description}

\subsection{Structure overview}

The ITEMB design includes two large monolithic pieces (the green ones) that constitutes the "Roof" (1) and the Rear Pressure Bulkhead (2). The two one piece elements are joined by a) Angles providing sealing on the Wing and on the Bulkhead (3) an (4), b) so called Elbow fittings (5) connecting Horizontal and Vertical Longerons, c) so called Gantry fittings (6) to join horizontal longeron to the Wing dorsal panel. Seat Rails are attached on longerons by dedicated fittings (8). Figure 1 gives also overall dimensions.

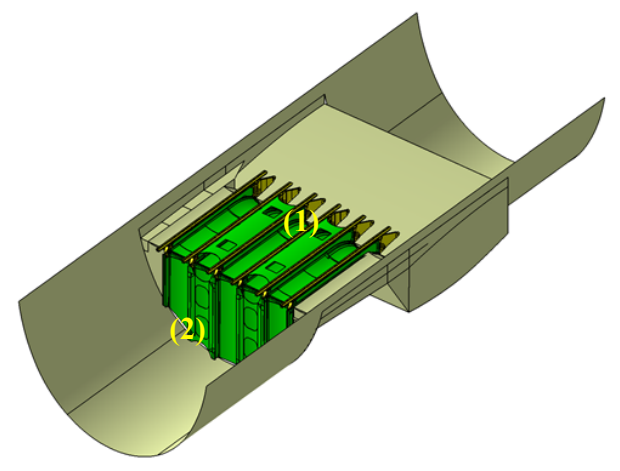




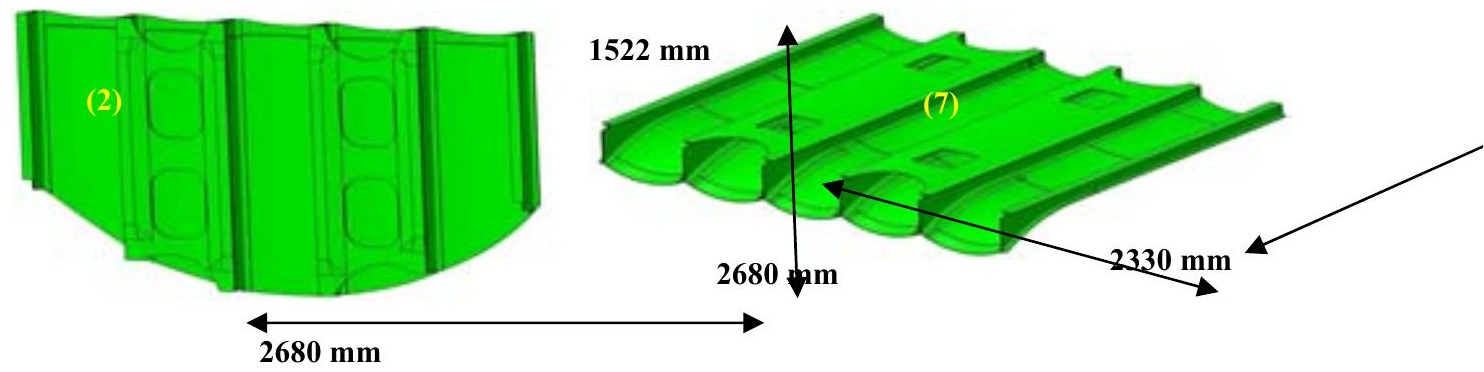

Fig. 1. Overall view.

Roof Longerons (9) are curved avoiding any notch and inner skins (7) are provided to increase longerons stiffness and give a provision for lateral stability, Figure 2.

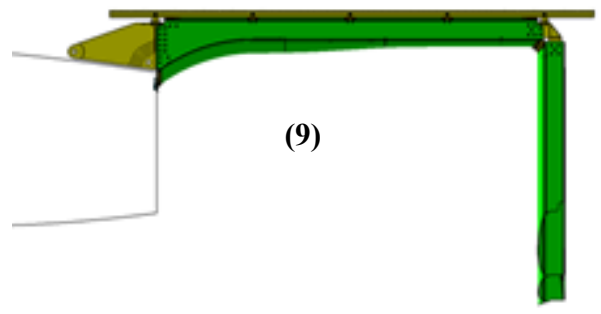

Fig. 2. Curved longeron.

Main plates and inner skins are "waved" for optimum pressure reaction and improved stability. The structure design required an optimum balance between strength and "flexibility" to decrease the effects of the wing induced deflections, Figure 3.
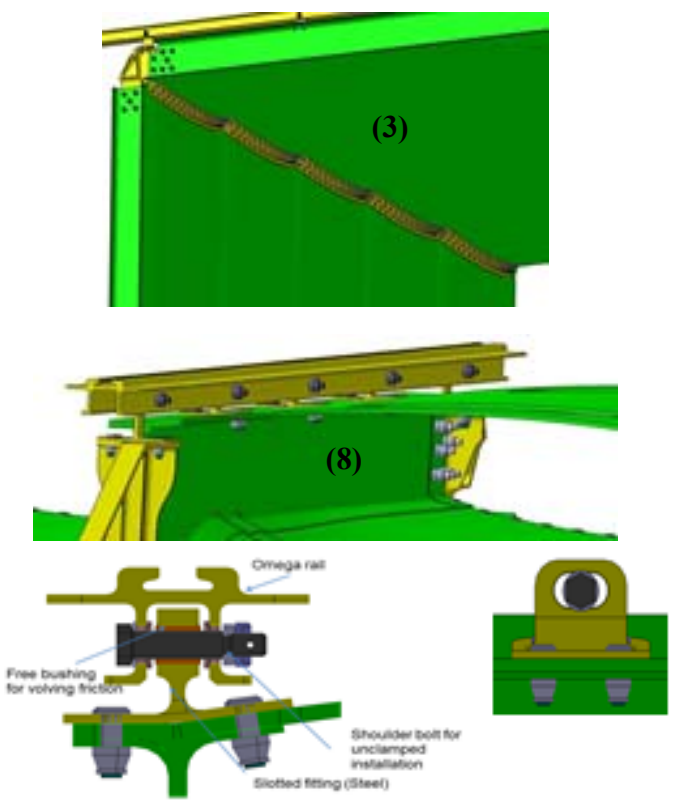

Fig. 3. Structural details.
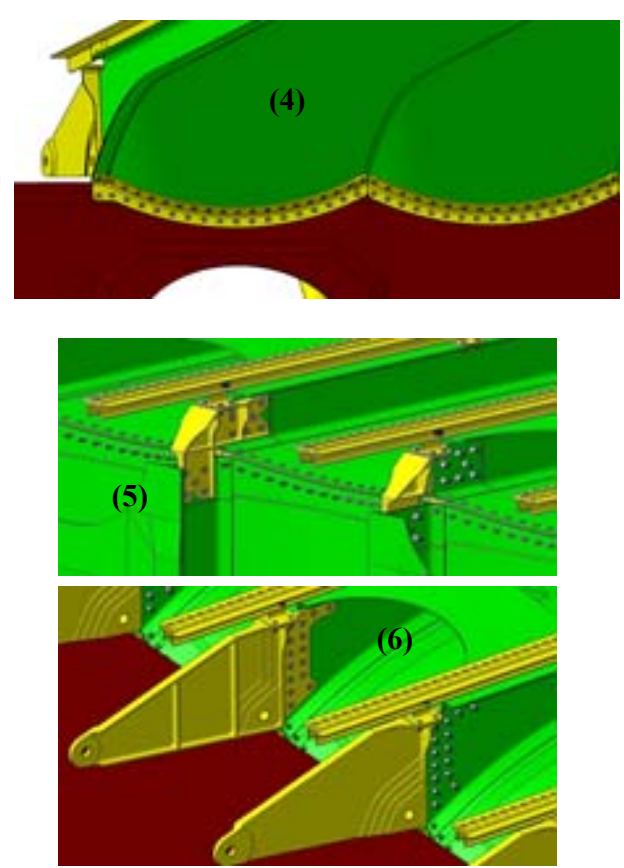


\subsection{Sizing guidelines}

Engineering-based methods, widely consolidated by the research team, have been addressed to the structural design, [5-6]. The materials adopted for numerical simulations are:

- Metal: Aluminium 7449 T7651;

- Composite: IMA/M21E medium grade $194 \mathrm{~g} / \mathrm{m}^{2}$.

while the sizing criteria implemented according to [7-9] are:

- Maximum Strain Criteria for Compression, Tension and Shear;

- Stability at UL (Eigenvalue).

Sol 101 has been used for Static Analysis applied to global FEM. A Global-Local approach has been used for Sol 105 addressed to stability analysis: displacements from Global FEM have been applied at boundary of Local FEM. Next pictures (Figs. 4, 5) show evidence that the structure is correctly working.

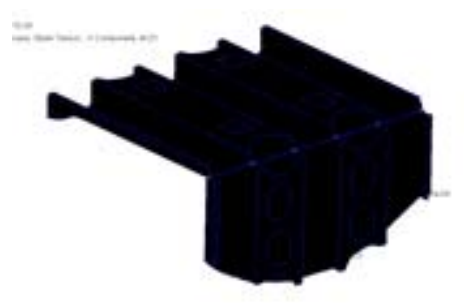

(a) Compression strain, $\mathrm{x}$ component

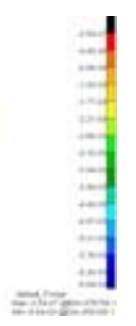

.

Fig. 4. Strain cut-off at Maximum Allowed.

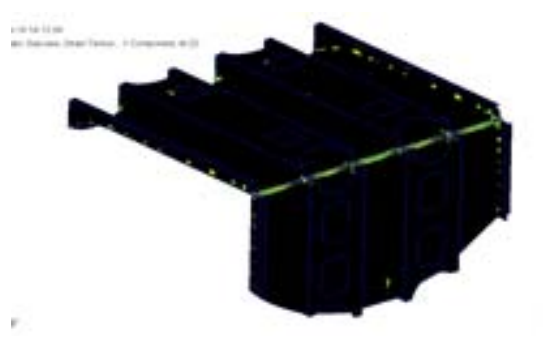

(b) Compression strain, y component
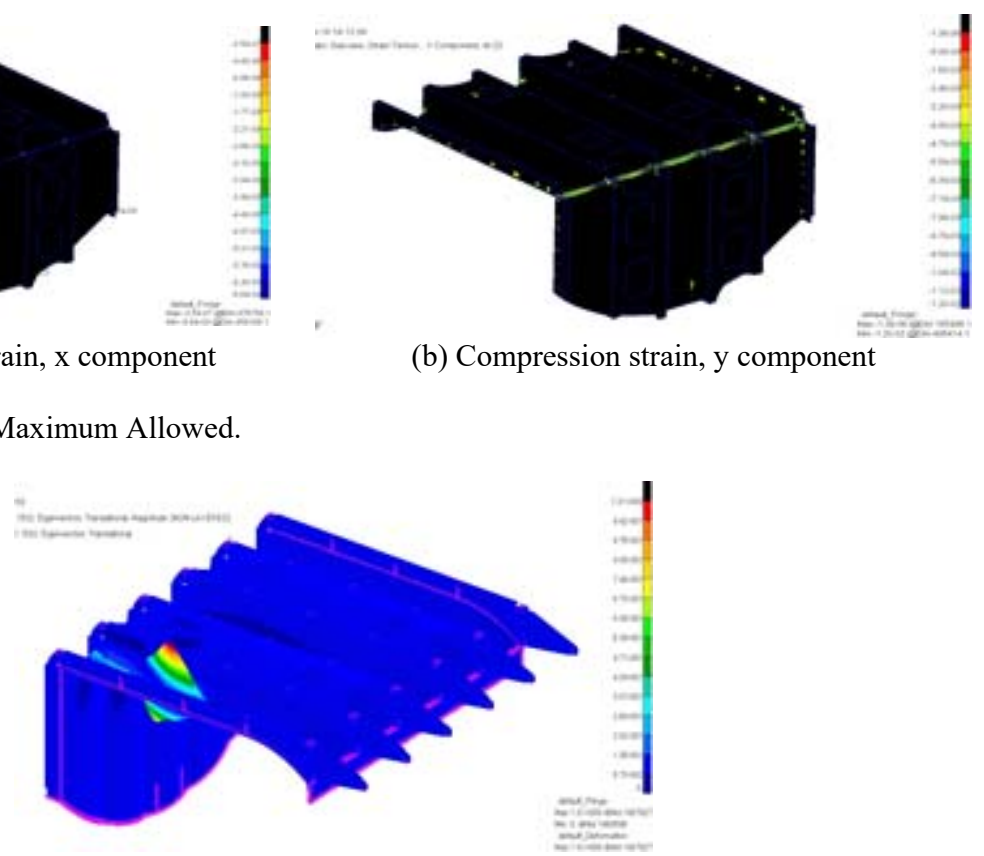

Fig. 5. Minimum Eigenvalue exceeding stated minimum value.

\section{Manufacturing principle}

\subsection{Main process and quality check}

The Manufacturing Process "bag against bag" adopted to produce the monolithic items is not in principle quite new: the application is original. The specific design/process successfully validated is unconventional and innovative. Tooling basic elements are $(1 \&$ ( 2 rigid shell, (3 Inner Plugs, (4 Outer Plugs, (5 Vacuum Bags and (6 Edge Sealant; the wet (fresh) assembly is positioned by plugs and compaction is given by vacuum between bags, Fig. 6. 

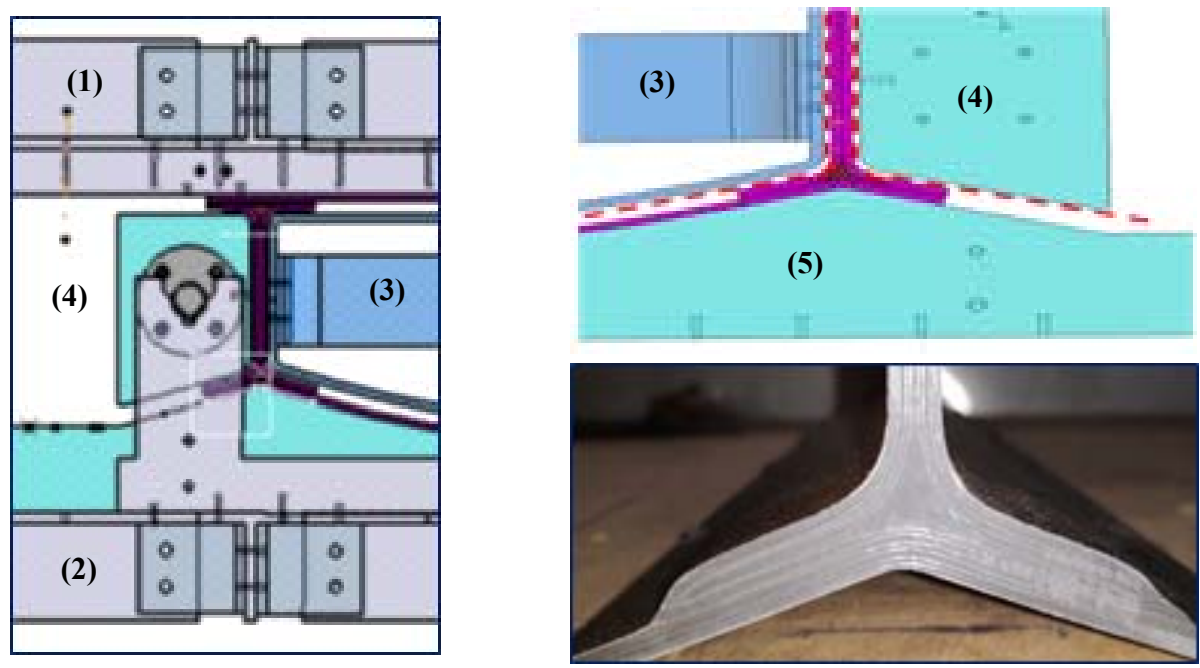

Fig. 6. Manufacturing main steps.

ITEMB proposed the "Hole to Hole" Assembly consisting (for both mating surfaces) in machining, after the cure and in contemporary stage of trimming, sacrificial material like Fiberglass to adjust at nominal the selected areas. After this operation also drilling at final size is performed. The Manufacturing concept, being new to the Consortium Partners, and new for the specific Structure has required production and inspection of small scale trials at growing level of complexity; at the end of the project a larger scale item has been produced. The testing campaign has included:

- Flat integrated box;

- "Waved skin" one-piece box;

- $\quad$ Large scale demo (1mx1m), in progress;

- $\quad$ Shaped longerons (hot drape formed);

- $\quad$ Shaped filler (hot drape formed);

- Trials to investigate drilling tolerances.

A collection of articles is shown: (a "wavy" box, (b hot drape formed curved longeron, (c radius filler, Figure 8.

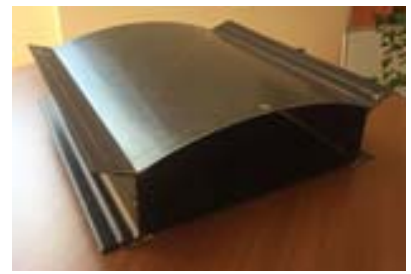

(a)

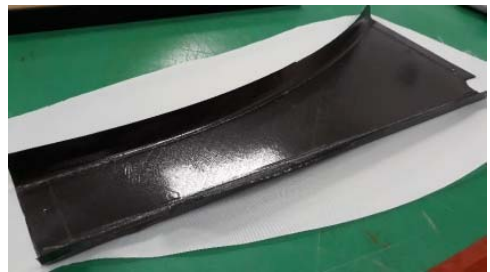

(b)

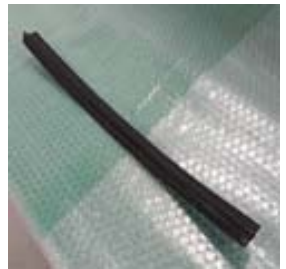

(c)

Fig. 8. Manufacturing trials.

Manufacturing testing have supported: 
- $\quad$ Tooling design;

- Manufacturing Flow of the specific integral item;

- Bagging approach;

- Process cycle;

- NDI;

- Analysis of Tolerances and potential Defects of the Process.

In the last Manufacturing Trial any waviness in radii areas and good compaction of fillers have not been detected, (due to the improved control of gaps between wet spar feet and wet skins during wet assembly), Fig. 9.

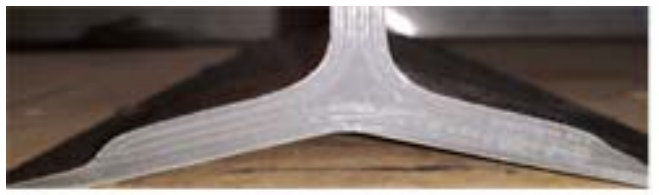

(a) Lower node

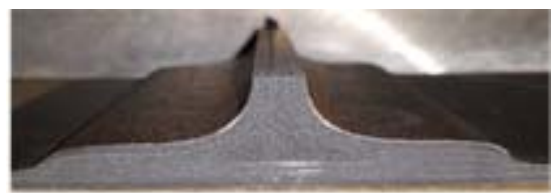

(b) Upper node

Fig. 9. Node sections.

US Inspection has shown very low porosity being attenuation minor than $6 \mathrm{~dB}$ everywhere. Punctual A-scans in the "node" have not shown any delamination or voids. About Geometrical Control:

Tolerance range "in"_for:

- $\quad$ Skins thickness;

- $\quad$ Radius of Longerons feet;

- Distance between best fit Longerons web plane.

Tolerance range "out" for:

- Longerons best fit plane position;

- $\quad$ Angle between Longerons best fit plane and nominal plane;

- Maximum distance between actual surface point and best fit plane.

Corrective actions on Plugs have been identified and execution is in progress on large.

Demo:

- Geometry check;

- Indexing system improvement;

- Stiffness improvement.

\section{Testing}

The whole experimental activity has been carried out in the Department of Industrial Engineering of University of Naples "Federico II", [10-12]. A critical detail has been identified in the ITEMB design of the MLGB consisting in the "node" at crossing of Longerons with Pressure plate. As risk mitigation action and to support the maturity of the design/process a static coupon test campaign has been set-up. The test, representative of the node filler area and producing a reliable radial stress, should show that first failure happens under about $5 \mathrm{kN}$. Coupons are cut from a dedicated article manufactured according to the in work process. The minimum Failure Load even if affected by Hot/Wet factor (assumed 0.75 ) and Scatter Factor (assumed 0.80 ) results $13.2 \mathrm{kN}$ as minimum value that is large enough to exclude any showstopper of the process. The Figures shows the failure mode and a typical force/displacement curve, Fig. 10. 


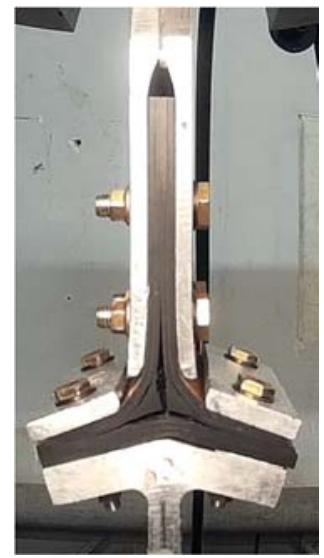

(a) Failure mode

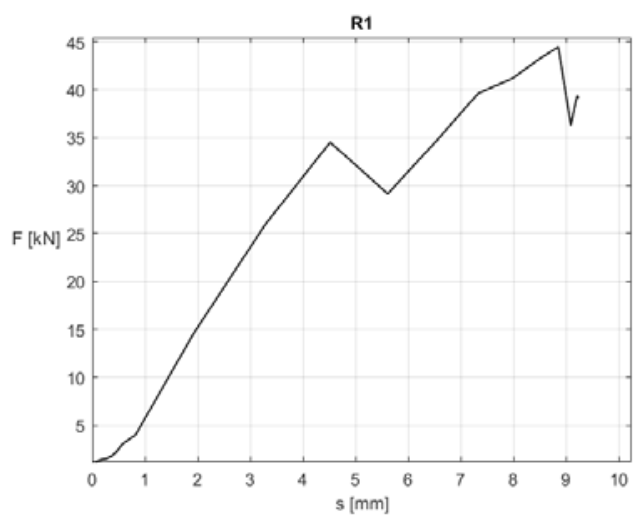

(b) Load trend

Fig. 10. Static tensile test.

\section{Costs}

The monolithic concept results in a huge assembly cost saving between 90-95\% with reference to a MLGB in the style of A350 that is made by a metallic Roof and CFRP Vertical Rear Pressure Bulkhead. A 5\% has been also estimated on parts manufacturing and Layout and balancing analysis of production lines results in 2 lines producing up to $100 \mathrm{~S} / \mathrm{S}$ per month if using "Hole to Hole" Assembly.

\section{Conclusions}

ITEMB Participants have acquired a new design and manufacturing technique that works, applicable also to other Aircraft components, upgrading their capabilities and European strength in composite structures manufacturing.

Participants consider ITEMB outcome more than encouraging for Fuselage tomorrow Project.

Participant disciplines cover Engineering, Manufacturing and Testing and so on the specific subject they are potentially a new fully Supply Chain.

Participants will work to enhance ITEMB design and manufacturing approach and give to ITEMB the best exploitation opportunities.

This project has received funding from the European Union's Horizon 2020 research and innovation programme under grant agreement No. 717190.

\section{References}

1. M. Viscardi, M. Arena, G. Barra, L. Guadagno, International Journal of Mechanics, 10, 376-382 (2016)

2. M. Viscardi, M. Arena, G. Barra, L. Guadagno, International Journal of Mechanics, 11, 51-57 (2017)

3. M. Arena, L. Vertuccio, G. Barra, M. Viscardi, L. Guadagno, AIP Conference Proceedings, 1981 (2018), Article number 020066 
4. G. Barra, L. Vertuccio, C. Naddeo, M. Arena, M. Viscardi, L. Guadagno, AIP Conference Proceedings, 1981 (2018), Article number 020149

5. C. E. Harris, J. H. Starnes, M. J. Shuart, Journal of Aircraft, 39(4), 545-560 (2002)

6. NASA, Design and Manufacturing Guideline for Aerospace Composites (NASA, 2005)

7. M. C. Y. Niu, Airframe Structural Design (Conmilit press 1td, 1990)

8. M. C. Y. Niu, Composite Airframe Structure (Conmilit press ltd, 1996)

9. ASTM D 5573-99, Standard practice for classifying failure modes in fiber-reinforcedplastic (FRP) joints (Annual Book of ASTM Standards, 2002)

10. M. Viscardi, M. Arena, G. Barra, L. Vertuccio, M. Ciminello, L. Guadagno, Proc. SPIE 10599, Nondestructive Characterization and Monitoring of Advanced Materials, Aerospace, Civil Infrastructure, and Transportation XII, 105991C (2018), doi: $10.1117 / 12.2295938$

11. M. Viscardi, M. Arena, M. Ciminello, M. Guida, C. Meola, P. Cerreta, Proc. SPIE 10599, Nondestructive Characterization and Monitoring of Advanced Materials, Aerospace, Civil Infrastructure, and Transportation XII, 105990N (2018), doi: $10.1117 / 12.2296420$

12. M. Viscardi, M. Arena, L. Guadagno, L. Vertuccio, G. Barra, Special Issue: 6th EASN Association International Workshop, International Journal of Structural Integrity (2017) 